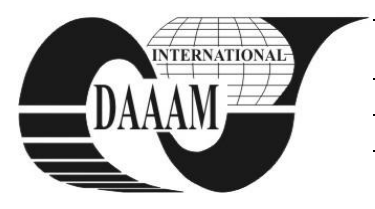

Annals of DAAAM for 2012 \& Proceedings of the 23rd International DAAAM Symposium, Volume 23, No.1, ISSN 2304-1382 ISBN 978-3-901509-91-9, CDROM version, Ed. B. Katalinic, Published by DAAAM International, Vienna, Austria, EU, 2012 Make Harmony between Technology and Nature, and Your Mind will Fly Free as a Bird Annals \& Proceedings of DAAAM International 2012

\title{
INTEGRATED PROCESS MODEL FOR WOOD MASSIVE PANELS PRODUCTION
}

\author{
OBUCINA, M[urco] \& HASANIC, S[anin]
}

\begin{abstract}
The production of solid wood panels is characterized by the effect of significant number of factors which have an influence on the quality of final product. Monitoring and understanding the mechanism of influencing factors presents the basis for surviving on the market. The purpose of this research was to give a survey of influencing factors and their systematization, ranking and comparison with the present state of work of the biggest companies from B\&H. On the basis of that, forming of the processing model should give guidelines for the future way of work by which customers requirements would be fulfilled. At the same time the purpose of this research is to give direction for future research in this field. The aim of this study paper can be defined through the methodology of defining influencing factors i.e. it is needed to identify, systematize and rank them and in that way to set up basis for control process and defining the requirements for the quality in communication supplier - customer. In this paper work, integrated process model is defined which should prevent the appearance of nonharmonization and should provide feedback in order to integrate customers requirements in the process of making the product.

Keywords: solid wood panels, influencing factors, quality control, proces model
\end{abstract}

\section{INTRODUCTION}

The quality is defined as the foundation of competitive advantages on the market as "harmonization with customers' requirements in regard to function, price, delivery deadline, safety, reliability, environment protection, guarantee, costs, consulting, etc"[1]. In regard to that, the quality management presents management through all phases of planning, production and usage of products, all for the purpose of fulfilling customers' requirements.

The production of solid wood panels presents the closed circle of manufacturing process starting from cutting of logs, steaming, drying, and technology processing to the production of solid wood panels. The production of the quality solid wood panels presents the basis for the further development of massive furniture industry which nowadays reaches the highest increase worldwide. Based on so far gained experience, the biggest problem in the industry of massive furniture production is non-quality glued wood massive panels. The wood massive panels are products used for the production of stairs, tables, kitchen cuttings boards, etc.

The main raw-material used by majority of manufacturers in $\mathrm{B} \& \mathrm{H}$ is beech board with standardized thickness 25,32 and $50 \mathrm{~mm}$, out of which they produce massive boards of thickness 20,27,40,43 and $45 \mathrm{~mm}$ [2].
Sustainability and development of an industrial sector is linked with its capability of continuous adjustment to the domestic and global environment. Development of this type of production can be considered only in correlation with the international trend. Behaviour of customers worldwide is more and more characterized through individualization in offer and demand. This is more and more applied for wood and furniture sectors depending on fashion design. . It is reflected in industrial production in appropriate organization form - in finalization based on requirements. [3].

\section{MATERIALS AND METHODS}

The issue of clearly defined customers' requirements is extremely exposed in this field. Requirements are most often descriptively stated and the task of producer is to interpret those requirements and implement them into clear and measurable characteristics of products.

Today there are more partial methods of the quality management that solve this issue, but there is a problem of defining the quality-managing model which would comprise all production segments and provide the stability of process.

In accordance with declared aims providing the quality in processes related to the material flow (from the raw-material to the final product), it is needed to make recognition, identification and management of influencing factors for the purpose of improving the processes and disabling the appearance of nonharmonized products.

The character of influencing factors on the production of solid massive panels is various where some of them can be presented with discrete values and evaluated in this way, while others values can only be presented with an adequate linguistic description with the certain accuracy degree. In that sense it is needed to find the way for analysis and evaluation of influence of both types of factors independently from the way of their presenting. The main problem that comes out in production of solid massive panels is there are no standards for certain classes of products i.e. there is no clear defined requirements for quality of solid massive panels. There are manufacturing specifications and trade norms that are subject to different interpretation by certain customers - what is the first class for Italian market it is the second class for Germany market. Therefore before starting the production, it is needed to include all customers' requirements in designing the product from the very beginning. 
The survey involved the most significant customers of wood massive boards in EU and B\&H. The purpose of implemented survey was to encompass various customers so the survey included the big shopping malls and final users i.e. manufacturers of massive furniture and stairs. The survey should give an answer on the following questions:

- Who are our customers?

- How do they make selection of suppliers?

- What are the conditions which they set in front of their suppliers regarding the standardization and other norms?

- What are customers' requirements regarding the quality and what are the ways of their evolution?

- Possible further tracks of improvement?

On that basis the survey has been conceptualized in the way to have three independent fields that give answers to aforementioned questions.

After survey, it is needed to perform analysis of data for the purpose of getting information about the following:

- Level of customers satisfaction,

- Fulfilment of customers requirements,

- Characteristics of processes, products and their trends and suppliers and

- Determination of the most significant influencing factors.

After implemented survey and data processing using the test of contingency we have got the value for $\chi 2$. The procedure called hi-quadrate test is usually used when it is about qualitative data or if on the basis of data, distribution is significantly differed from normal. It is only calculated with frequencies and it is not allowed to enter any measurable units [4].

By this procedure it will be checked whether gained answers statistically and significantly derogate from all criteria i.e. requested influencing factors from the usual values for the values of $\mathrm{p}=0,05$ and whether gained value is below permitted value of 9.4888 .

\begin{tabular}{|c|c|c|}
\hline Criteria & Values $\chi^{2}$ & Results \\
\hline Capacity & 1,8 & Satisfactory \\
\hline $\begin{array}{l}\text { Finger joint and planning } \\
\text { machine for the surface at } \\
\text { which the glue is put on }\end{array}$ & 7,5 & Satisfactory \\
\hline Capacity harmonization & 5,3 & Satisfactory \\
\hline $\begin{array}{l}\text { Managing the warehouse, } \\
\text { relation with supplier and } \\
\text { raw material quality }\end{array}$ & 7,36 & Satisfactory \\
\hline Thermal treatment & 5,3 & Satisfactory \\
\hline $\begin{array}{l}\text { Technical-technological } \\
\text { capability of the company }\end{array}$ & 5 & Satisfactory \\
\hline Moisture contents & 4,37 & Satisfactory \\
\hline Small assortments & 7,86 & Satisfactory \\
\hline Price & 9,5 & Unsatisfactory \\
\hline Uneven quality of delivery & 14,1 & Unsatisfactory \\
\hline Delivery deadline & 6,4 & Satisfactory \\
\hline
\end{tabular}

Tab. 1. Values of $\chi^{2}$ for all criteria [5]

In this way it has been proven that customers' basic criteria for making decision to work with certain manufacturers of wood massive panels are:
- Capacity,

- Selection of finger joint and planning machine for the surface at which the glue is put on,

- Capacity harmonization between production units

- Managing the warehouse, relation with supplier and raw material quality

- Thermal treatment of wood,

- Technical-technological capability of the company,

- Moisture contents of the product - wood massive panels,

- Assortments of products and

- Delivery deadline.

The integrated process model should prevent the appearance of nonharmonization and should provide feedback in order to directly integrate customers' requirements in the process of making the product.

Providing the quality by adoption of requirement standard ISO 9001 can be sufficiently enough for quality process. The principle of constant improvements states that depending on specificity of certain production type, some aspects of quality management must be emphasized and stressed more as crucial in the quality management process. In accordance with that, the following processes have to be emphasized for the functioning of wood massive board production process:

- Defining the map of process,

- Determination of critical and controlling points in quality management,

- Defining the model for improvement of quality production process, and

- Providing the feedback for prevention of appearance of nonharmonized products.

\section{RESULTS OF DISCUSSION}

The research of companies' mode of operation, companies that manufacture the solid massive panels, included:

- visits to companies and monitoring of work,

- sending questionnaires and

- Discussion of results with company management.

The approach to the analysis of mode of operation and position of the company must be seen as multiple problems. The following segments have to be included:

- Activities that preceded the production process through environment requirements and activities for solving relations with suppliers.

- Activities of process resulting with products

- Post selling activities (transport, maintenance, the mode of solving claims, direction of further possible improvements).

As the result, all previous analysis should have determination mode of the integrated process model of production which connect significant information from the market and requirements for final product.

As the result of implementing this model, the companies producing the solid massive panels could expect the following: 
- It should present the tool for improving the system of the quality management,

- Provide preconditions for integration into global market flows, and

- Implementation of this model, respecting the principles of continuous improvement, enables to have satisfied customers' by achieving better business results of the company in the end.

On the basis of aforementioned, taking into consideration the most significant influencing factors emphasized by costumer and by implementing it to the working processes through quality loop, it can be concluded that the biggest nonharmonization could show up in:

- Clearly defining customers' requirements regarding the technical characteristics of product, assortments and in satisfaction of customers' need regarding the quantity of certain type of products,

- Impossibility of production and supply of sufficient quantity of raw material,

- Designing the quality control and monitoring the significant parameters including the prevention of reproduction of nonharmonized products,

- Delivery mode and respecting given deadlines.

\section{INTEGRATED PROCESS MODEL}

Through the analysis of solid massive panels' production, we can define the picture related to the quality model looking from the standpoint of:

- Size of manufacturing plant,

- Owner of process,

- Process.

The size of the manufacturing plants plays very important role in creating the picture about the manufacturer of solid massive panels. The survey covered five biggest manufacturers in $\mathrm{B} \& \mathrm{H}$ and the following can be concluded from given answers:

- All companies are private properties and belongs to the category of medium enterprises,

- There are significant capacities in the part of primary wood processing and thermal wood treatment,

- From technical-technological point of view the most modern machines are dominated which do not get behind from the technology of EU manufacturers and worldwide.

The basic aim is to present integrated process model of quality organization through the prism of processes that characterized these plants and their net with environment.

By the analysis which should include the production, supplier relations, mode of selling and relation with customers and their combination, the model of actual trends can be created regarding the further improvement of the company. By measuring parameters and data in all segments of quality loop in the company including data from the market collected through quantitative and quality research and constant testing of product, all sources for possible improvement of the product and quality management are circled.
With the company quality model for the production of solid massive panels all standard requirements, organizational structure, mapping of all processes, presenting the link between processes and their documenting as the applying of quality tool are included which together complete this model. (Fig.1.)

In accordance with that, for the functioning of production process of solid massive panels the following processes have to be emphasized:

- Analysis of quality perception i.e. quality perspective by the user,

- GAP analysis,

- Defining the House of quality which will include the previous analysis,

- Defining and ranking influencing factors through the cause-and effect diagram, and

- Monitoring and collection of feedback from the production and by customers through $\mathrm{ABC}$ analysis and statistic process control SPC.

On the basis of aforementioned it is needed to define model which will include all mentioned analysis and tools.

In the case of monitoring the quality function as the process model i.e. concept in which the central role is focused on the user i.e. customer, the individual customer requirements related to the product are fundamental. Here is very important to emphasize that the survey of customers showed nonharmonization between certain requirements depending who are the buyers of the product.

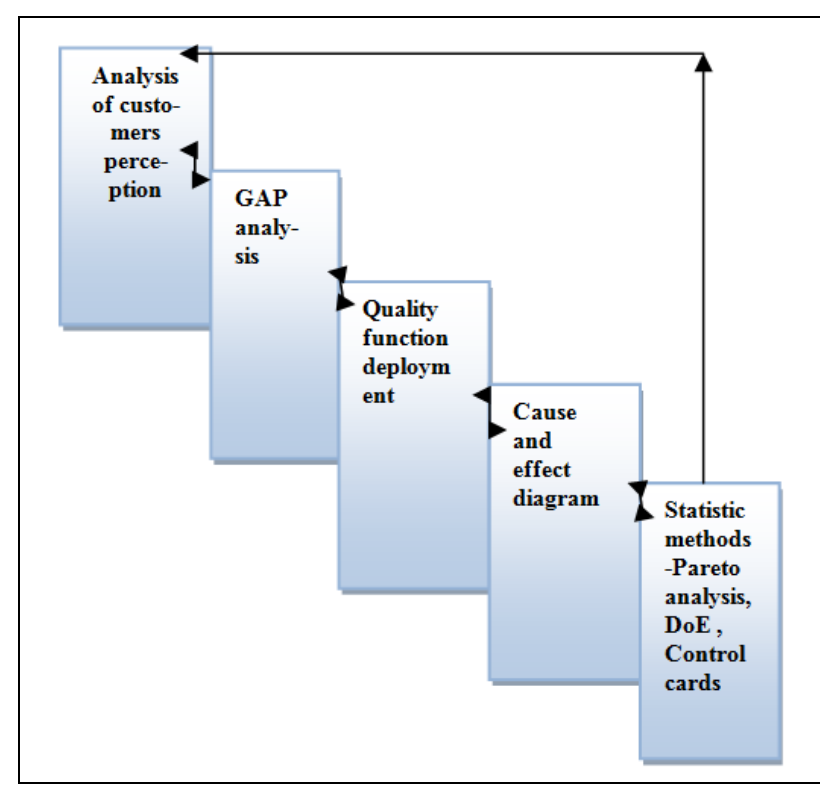

Fig.1. Integrated process model of improvement of production process quality

Differences have been found in:

- The ordering mode of product - Agent and trade companies have agreed to make orders on the basis of established trade norms and standards, while orders toward manufactures of furniture are made according to clearly defined criteria for the company in the form of norms which are delivered together with the order.

- Selection of strategic instrument - Balanced scorecard and SWOT analysis selected for agent and trade 
companies while the Competition Analysis is most significant for the manufacturers.

- Discrepancies related to the company capacity capability - for trade companies it is very important while for manufacturers of furniture and stairs this does not play an important role.

GAP analysis indicates discrepancies between the existing and desirable state and what has to be done in order to overcome the gap. In this way we can estimate our own possibilities i.e. what resources we need in order to overcome existing gap between present and desirable state. Having the survey of customers and comparing it with the results gained from the survey of manufacturers we can say that sources of the gap can be expected in following:

- Fulfilling the requirements of customers regarding the moisture of products,

- Fulfilling the requirements of customers regarding the sufficient quantity of certain product respecting the deadline of supply,

- Fulfilling the requirements of customers regarding the persistence of quality between the supplies due to the issue of raw-material purchase,

- Fulfilling the requirements of customers regarding the product assortments, and

- Clear definition of product quality i.e. what the customer expects.

After defining the gap and the source of gap it is needed to undertake measures for correction of mistakes what we expect to get by defining the integrated process model through QFD tool. The estimation of a degree of improvement of the Quality Management System-a (QMS) is extremely complex because of risks of inadequate choice of direction and mode of improvement as well as necessary resources for such attempt. The Quality Function Deployment - QFD method provides improvement of QMS in accordance with requirements of users as one of the most important factors in the quality management. Respecting the "voice of costumers", QFD method initiates and directs changes of QMS in sense of effective and efficient functioning of business system. QFD method helps in positioning of the company at the market and creates needed conditions for establishing feedback and estimation of achieved improvement through relevant information for an adequate decision on direction and improvement degree of QMS and its elements.

In order to monitor influencing factors, at very beginning they have to be clearly defined and presented as simple as possible. As the result we will get better monitoring of characteristics of process and possibility for clear defining and organizing the quality control.

Next steps which have to be implemented by manufactures of solid massive panels after presenting and defining the influencing factors and through control cards and Pareto analysis are to organize the functioning of quality control and set up preventive action in order to avoid the appearance of nonharmonized products. Here is very important to emphasize that this process is constant and by applying the model with achieved results it is needed to go back on the beginning in order to reexamine input into the process.

\section{CONCLUSION}

In this paper work it is presented the research of the thirteen currently biggest customers of solid massive panels and we got results which have been statistically processed. Results shows that there are certain factors at which customers specially pay attention and they have been ranked on the basis of gained results.

It is clearly understood that there is twofold character of factors which are emphasized by customers. First are those related to the mode of production organization, capacitive capability of the company and relations with customers while the second ones are those of technical parameters which all manufacturers have to meet in order to have recognized product.

Also, the problem of defining the model of quality control - process model which would include all segments of production and provide stability of process has been processed.

On the basis of the survey which was implemented between the biggest manufacturers in $\mathrm{BiH}$ we got indicators of the mode of production and comparing them with customer's requirements from the first part we got certain segments out of the quality loop which have to be specially emphasized for this type of production. In this way the process model has been defined.

Generally, nowadays the wood industry present extremely important branch of the economy in $\mathrm{BiH}$. All researches made in this field and their implementation within the industry presents an imperative for all who are involved in this branch of industry.

On the basis of previous and aforementioned conclusion, in further paper works authors are planning the following researches:

- research the mode of evolution and mechanism effects, individually for each of significant influencing factor,

- to research in details the application of each quality tool, included in the model,

- to research in details the mode of work of the company for production of solid massive panels on the basis on data gained from this research

\section{REFERENCES}

[1] Haist, F/Fromm H. (1989) : Qualitaet im Unternehmen, Prinzipien - Methoden-Techniken; Muenchen,Wien

[2] Brdarević, S., Hasanić, S. (2009) : House of quality for the massive wood panels, Quality 2009, pp. 57 - 62, ISSN 15129268, University of Zenica, Faculty of Mechanical Engineering, Zenica

[3] Working group , (2004): Strategy on development of industrial processing of wood and paper, Zagreb,

[4] Maglić , Leon (2008) : „Researches on efficiency system of quality management" - PhD, Faculty of Mechanical Engineering and Naval Architecture, University in Zageb, Zagreb

[5] Hasanić S., Brdarević S., Obucina M. (2011) : Monitoring of wood solid panel quality using the cause-and-effect diagram, Development trends in economic and management in wood processing and furniture manufacturing, pp. 51 -56 , ISBN 978961-6144-31-5, Proceedings, Wood EMA, i.a., Kozina, Slovenia 